\title{
O DISCURSO SOBRE A DISLEXIA NO DSM-5 E SUAS IMPLICAÇÕES NO PROCESSO DE MEDICALIZAÇÃO DA EDUCAÇÃO
}

\author{
EL DISCURSO SOBRE LA DISLEXIA EM EL DSM-5 Y SUS IMPLICACIONES EM EL \\ PROCESSO DE MADICALIZACIÓN DE LA EDUCACIÓN
}

\section{THE DISCOURSE ON DYSLEXIA IN THE DSM-5 AND ITS IMPLICATIONS IN THE PROCESS OF MEDICALIZATION OF EDUCACION}

\author{
Elisabeth da Silva ELIASSEN ${ }^{1}$ \\ Ana Paula de Oliveira SANTANA ${ }^{2}$
}

RESUMO: A medicalização da infância e da adolescência se articula com a medicalização da educação com relação às "doenças do não aprender". Nesse contexto, o diagnóstico da Dislexia é legitimado pelo DSM, Manual Diagnóstico e Estatístico de Transtornos Mentais, utilizado pelos profissionais da saúde. O objetivo deste artigo é analisar o modo como as classificações diagnósticas do DSM-5 faz efeito na medicalização do processo de apropriação da leitura. Os dados foram analisados a partir da Análise Dialógica do Discurso. Os resultados revelaram que o discurso médico, materializado no texto do DSM, implica diretamente na medicalização da educação. O DSM-5 apresenta uma versão da Dislexia que desconsidera a história e o contexto sociocultural no qual os estudantes ou adultos em circunstâncias não escolares, manifestam ou têm produzido sintomas na leitura. A ideologia na qual o documento se baseia se insere numa perspectiva biologizante, na qual os problemas específicos à aprendizagem do ler decorrem de desordens neurobiológicas e, portanto, podem ser medidos facilmente, por meio de medidas padronizadas. As consequências desse modo de olhar têm desdobramentos significativos que marcam a trajetória escolar e contribuem com a configuração de uma história que passa a ser marcada pela incapacidade de aprender.

PALAVRAS-CHAVE: Dislexia. DSM-5. Medicalização. Diagnóstico.

RESUMEN: La medicalización de la infancia y la adolescencia está vinculada a la medicalización de la educación en relación con las "enfermedades del no aprendizaje". En este contexto, el diagnóstico de Dislexia está legitimado por el DSM, Manual diagnóstico y estadístico de los trastornos mentales, utilizado por los profesionales de la salud. El propósito de este artículo es analizar cómo las clasificaciones de diagnóstico DSM-5 tienen un efecto en la medicalización del proceso de apropiación de lectura. Los datos se analizaron mediante un análisis del discurso dialógico. Los resultados revelaron que el discurso médico, materializado en el texto del DSM, implica directamente la medicalización de la educación. DSM-5 presenta una versión de la Dislexia que ignora la historia y el contexto sociocultural

\footnotetext{
${ }^{1}$ Universidade Federal de Santa Catarina (UFSC), Florianópolis - SC - Brasil. Doutoranda No Programa de Pós-graduação em Linguística. ORCID: https://orcid.org/0000-0002-3304-2931. E-mail: beth_eliassen@yahoo.com.br

${ }^{2}$ Universidade Federal de Santa Catarina (UFSC), Florianópolis - SC - Brasil. Professora Associada no Curso de Fonoaudiologia e no Programa de Pós-graduação em Linguística. Doutorado em Linguística (UNICAMP). ORCID: https://orcid.org/0000-0002-9508-9866. E-mail: anaposantana@hotmail.com
} 
en el que los estudiantes o adultos en circunstancias no escolares, manifiestan o han producido síntomas en la lectura. La ideología en la que se basa el documento se inserta en una perspectiva biologizante, en la cual, los problemas especificos para el aprendizaje de la lectura son el resultado de trastornos neurobiológicos y, por tanto, pueden medirse fácilmente, a través de medidas estandarizadas. Las consecuencias de esta forma de ver tienen características significativas que no solo marcan la trayectoria de la escuela, sino que también contribuyen a la configuración de una historia que está marcada por la incapacidad para aprender.

PALABRAS CLAVE: Dislexia. DSM-5. Medicalización. Diagnóstico.

ABSTRACT: The medicalization of childhood and adolescence is linked to the medicalization of education in relation to "diseases of not learning". In this context, the diagnosis of Dyslexia is legitimized by the DSM, Diagnostic and Statistical Manual of Mental Disorders, used by health professionals. The purpose of this article is to analyze how the DSM-5 diagnostic classifications have an effect on the medicalization of the reading appropriation process. The data were analyzed using a Dialogic Discourse Analysis. The results revealed that the medical discourse, materialized in the DSM text, directly implies the medicalization of education. The DSM-5 presents a version of Dyslexia that disregards the history and the socio-cultural context in which students or adults in non-school circumstances, manifest or have produced symptoms in reading. The ideology on which the document is based is inserted in a biologizing perspective, in which, the specific problems to the learning of reading result from neurobiological disorders and, therefore, can be easily measured, through standardized measures. The consequences of this have significant consequences, which not only mark the school trajectory, but also contribute to the configuration of a story that is marked by the inability to learn.

KEY WORDS: Dyslexia. DSM-5. Medicalization. Diagnosys.

\section{Introdução}

A medicalização é definida como o processo em que questões de ordem coletivas, sociais e políticas são convertidas em questões biológicas e individuais. Nesse sentido, isentase de responsabilidade as instâncias de poder na qual os problemas são originados e perpetuados (MOYSÉS; COLLARES, 2013).

Para pensar sobre a medicalização da educação, especificamente do processo de apropriação da leitura, faz-se necessário refletir sobre a aprendizagem e o ensino da leitura. Além disso, deve conduzir necessariamente a uma reflexão acerca do lócus no qual ela se constitui e no qual ela se materializa - a escola e, em alguns casos, a clínica. É nesse contexto que se legitima a construção das "doenças do não aprender", contexto no qual é discutido o que se entende por Dislexia. 
O discurso hegemônico reconhece a Dislexia como uma incapacidade específica de aprendizagem, de causa neurobiológica, caracterizada por dificuldades no reconhecimento da palavra e nas habilidades de decodificação e soletração, resultantes de um déficit do componente fonológico. Tais condições poderiam resultar, ainda, em dificuldades relacionadas à compreensão de leitura, escassas experiências com textos, implicando assim o desenvolvimento lexical e conhecimento de mundo. Essas manifestações seriam incompatíveis com a instrução acadêmica ou com as habilidades cognitivas (MOUSINHO; NAVAS, 2016).

$\mathrm{Na}$ prática, o que ocorre é que, quando os estudantes não correspondem ao que a escola predetermina como normalidade, essa quebra de expectativa é atribuída a um transtorno neurobiológico e intrínseco ao sujeito. Alguns autores analisam essa questão a partir do conceito de dispositivo de Foucault (1977), ao afirmarem que, por meio dos discursos científicos, os dispositivos da medicalização produzem subjetividades e translocam as linhas de saber, sendo a escola uma máquina concreta da medicalização, pois, é nela que se criam lugares para ocupar regimes de luz e os enunciados engendram e medicalizam o ser e o aprender (CHRISTOFARI; FREITAS; BAPTISTA, 2015). De outro lado temos os professores influenciados fortemente pelo discurso da psiquiatria que acabam por contribuir com o enraizamento da medicalização no ambiente educacional (ELIASSEN, 2018; GIROTO; ARAUJO; VITTA, 2019), na medida em que priorizam hipóteses biomédicas em detrimento do conhecimento pedagógico (AZEVEDO, 2018). A Dislexia inicia-se, assim, na escola, com o encaminhamento, pelo professor, do aluno considerado como o que não aprende, embora esse mesmo professor desconheça o conceito de Dislexia (ELIASSEN, 2018).

Quanto às famílias, essas também não estão à margem deste processo, o que se observa é uma forte adesão dos pais à medicalização das dificuldades dos filhos, visto que a busca por um laudo e uma explicação médica são os primeiros recursos utilizados pelas famílias (AZEVEDO, 2018). Assim, a família busca por um diagnóstico que justifique o "não aprender da criança". Dessa maneira, o discurso médico sobre as causas genéticas é ressaltado em detrimento das questões escolares, subjetivas e culturais. O peso dos exames médicos sobrepõe-se às condições socioculturais do aluno (má alfabetização, hábitos restritos de letramento, bullying, aspectos emocionais). É assim também que a "anormalidade" (im)posta pelo diagnóstico de Dislexia é legitimada pela família.

Propostos inicialmente para o campo da saúde, os manuais diagnósticos parecem cumprir essa função classificatória, demarcando o que pertenceria à ordem do normal e do 
patológico. O DSM foi criado, em 1953, pela Associação Psiquiátrica Americana (APA), com uma lista de 106 desordens, configurando-se o primeiro manual de transtornos mentais com enfoque clínico (ARAÚJO; NETO, 2014; MOYSÉS; COLLARES, 2013). Até esse momento, os transtornos mentais estavam listados como parte integrante da Classificação Estatística Internacional de Doenças e Problemas Relacionados com a Saúde (CID). Em 1968 foi lançada a segunda edição, organizada em conjunto com o CID-8. O DSM-I e DSM-II apresentam por característica categorizar os transtornos, discriminando os que possuem base orgânica dos não orgânicos (MOYSÉS; COLLARES, 2013; ARAÚJO; NETO, 2014). A terceira edição, no entanto, rompe com essa lógica e passa a considerar que toda patologia psíquica tem origem biológica, desconsiderando a narrativa dos pacientes (ARAÚJO; NETO, 2014; CAPONI, 2015). Em 1994 a APA lançou a quarta edição, que foi revisada em 2000 e intitulada de DSM-IV-TR, sendo utilizada até o início de 2014 (ARAÚJO; NETO, 2014), quando foi publicada a mais polêmica entre todas as versões: o DSM-5.

Com o objetivo de harmonizar as classificações, o DSM-5 e o CID-11 foram planejados conjuntamente. Pactuadas, formaram equipes de "força-tarefa" motivadas pela necessidade de facilitar a coleta de dados dos transtornos mentais, pesquisas epidemiológicas, ensaios clínicos e testes para novos tratamentos, aplicabilidade global dos resultados e a replicação dos estudos em diferentes países. Assim, as equipes organizadoras optaram por uma estrutura organizacional de trabalho compartilhada (APA, 2013). Essa estratégia de alinhar os documentos, ainda que com a justificativa virtuosa de facilitar o trabalho do clínico, implicitamente desvela um empreendimento de biopoder, uma aliança entre forças hegemônicas, literalmente, "forças-tarefas" unidas em prol da certificação do próprio discurso ideologicamente marcado pela exclusão e medicalização (BAKHTIN, 2014).

Sem a menor dúvida, o DSM-5 é a edição mais criticada dentre todas as versões anteriores - embora considerações já viessem sendo dirigidas ao DSM pelo menos desde a terceira edição - muito em razão de alguns pesquisadores considerarem que o consenso terminológico almejado pelo manual, no qual as patologias devem ser padronizadas, a fim de encaixarem-se na classificação diagnóstica, praticamente extinguiria a comunicação entre clínicos, a finalidade acadêmica, dentre outras demandas (DUNKER, 2014).

Em razão disso, movimentos de resistência e diferentes fóruns de discussão têm fortalecido a luta contra a medicalização balizada pelos manuais classificadores. De proporção internacional, o Movimento Stop-DSM, originado na França no ano de 2010, manifesta-se contrário à existência de um código diagnóstico que seja único, obrigatório e universal (CAPONI, 2014). 
É importante ressaltar que as apreciações negativas dirigidas ao DSM-5 começaram antes mesmo de sua publicação. As principais questões levantadas referiram-se a 3 pontos: (i) a falta de consistência científica; (ii) o favorecimento da prática médica e (iii) a forte relação com o mercado da indústria farmacêutica (MARTINHAGO; CAPONI, 2019). Acrescenta-se a essas questões, claro, a forte tendência em multiplicar diagnósticos desnecessários (CAPONI, 2015).

Thomas Insel, diretor do National Institute of Mental Health (NIMH), a maior organização científica dedicada à pesquisa, compreensão, tratamento, prevenção e promoção da saúde mental é um desses críticos (CAPONI, 2015). Pouco antes da publicação do manual ele declarou que o instituto passaria a não mais pautar-se no DSM, por considerar tratar-se de uma lista de sintomas construída com base em suposições e convenções. A crítica, porém, foi posta em xeque quando se percebeu que Insel na verdade teve sua expectativa frustrada pelo DSM não ter indicado marcadores biológicos e estudos científicos que validassem os diagnósticos (CAPONI, 2015).

Outro nome que causou grande surpresa ao direcionar críticas ao DSM-5 foi Allen Frances, responsável pela equipe que elaborou a versão anterior, o DSM-IV. Para Frances as fragilidades do DSM podem ser divididas em dois grupos: o primeiro refere-se às escolhas lexicais, as quais poderiam levar a erros de interpretação; e a segunda tem relação com erros na elaboração, redação, indefinições e suposições de patologias, o que na opinião dele pode conduzir a uma verdadeira pandemia de transtornos mentais. Francis aponta, ainda, que o DSM-5 poderia promover milhões de "falsos positivos", os quais acarretariam inúmeros tratamentos desnecessários, caros e nocivos (CAPONI, 2014).

Dunker (2014) enfatiza que o DSM-5 acaba por ser alvo de muitos psiquiatras por não corresponder às descobertas científicas, apresentando apenas novas denominações para os sintomas e conceituações de síndromes.

Neste cenário, há ainda questionamentos acerca da natureza da relação entre a indústria farmacêutica e membros da APA, bem como sobre o interesse econômico no financiamento de determinadas pesquisas e na própria formulação do DSM (CAPONI, 2014).

O ponto crucial de discussão parece ser, então, a relevância de apreender a ampliação da psiquiatria biológica, na qual caracteriza e classifica como transtorno mental o que antes era compreendido como subjetivo, como parte de um sujeito, que é histórico, é social e vinculado a uma cultura.

A partir desse contexto, o objetivo deste artigo é analisar o modo como as classificações diagnósticas, em especial o Manual Diagnóstico e Estatístico de Transtornos 
Mentais (DSM), em sua quinta edição, faz efeito na medicalização do processo de apropriação da leitura. Quer-se, especificamente, refletir como o DSM-5 discursiviza sobre a Dislexia e a relação desse discurso com a patologização da educação. A discussão será conduzida a partir da Análise Dialógica do Discurso (ADD).

\section{O Transtorno específico de Aprendizagem no DSM-5: uma nova roupagem para antigos sintomas}

A ideia da normatização dos transtornos de aprendizagem subjaz a adoção intencional de conceitos utilizados na tentativa de legitimar dificuldades como "doenças"; são eles: neurobiológico; especifico; persistência; transtorno; dentre outros. Perpassam, então, concepções voltadas à vigilância, medição, controle, avaliações disciplinares, padronizações, buscando reacentuar o discurso biológico. Os signos selecionados para compor o manual revelam posições axiológicas, ideologias, que favorecem determinados lugares e grupos sociais (BAKHTIN, 2014).

No DSM-5, a Dislexia é designada como Transtorno Específico da Aprendizagem, podendo abarcar dificuldades nos domínios de leitura, expressão escrita e matemática, configurando um quadro mais global, mas com codificações específicas para cada subhabilidade alterada. No caso das dificuldades específicas ao domínio da leitura, ou seja, em se tratado de um caso "puro" de Dislexia, o clínico deverá indicar tratar-se do Transtorno Específico da Aprendizagem com prejuízo na leitura. Contudo, essa mudança não foi aceita sem relutância por pesquisadores e profissionais atuantes nessa área (MOUSINHO; NAVAS, 2016). E, após muito debate, o DSM-5 incluiu uma nota indicando que a Dislexia seria um termo alternativo utilizado para se referir a um padrão de dificuldades particulares à leitura. Não se trata apenas de substituir um nome por outro. O que ocorre é a reacentuação de um discurso. Adotar Transtorno específico ao invés de Dislexia implica uma mudança de olhar da própria definição de Dislexia. Chama atenção aqui a necessidade de referenciar explicitamente o termo específico, apesar de conceitualmente o quadro caracterizar-se como global nessa visão. Então a Dislexia não estaria mais circunscrita a uma dificuldade na leitura? Qual o interesse em modificar o conceito? A que discursos outros essa resposta se orienta? A transição de Dislexia, Discalculia, Disgrafia, Disortografia e outros "DIS" para Transtorno Específico de Aprendizagem busca assegurar a possibilidade de comorbidades, um forte discurso da atualidade, ao mesmo tempo em que reenuncia à delimitação do transtorno neurobiológico. O manual orienta que o diagnóstico do Transtorno Específico de 
Aprendizagem seja determinado a partir de quatro critérios diagnósticos ${ }^{3}$ (Figura 1), os quais deverão ser preenchidos pelo clínico.

Figura 1 - Quadro de Critérios do DSM-5 para o diagnóstico da Dislexia

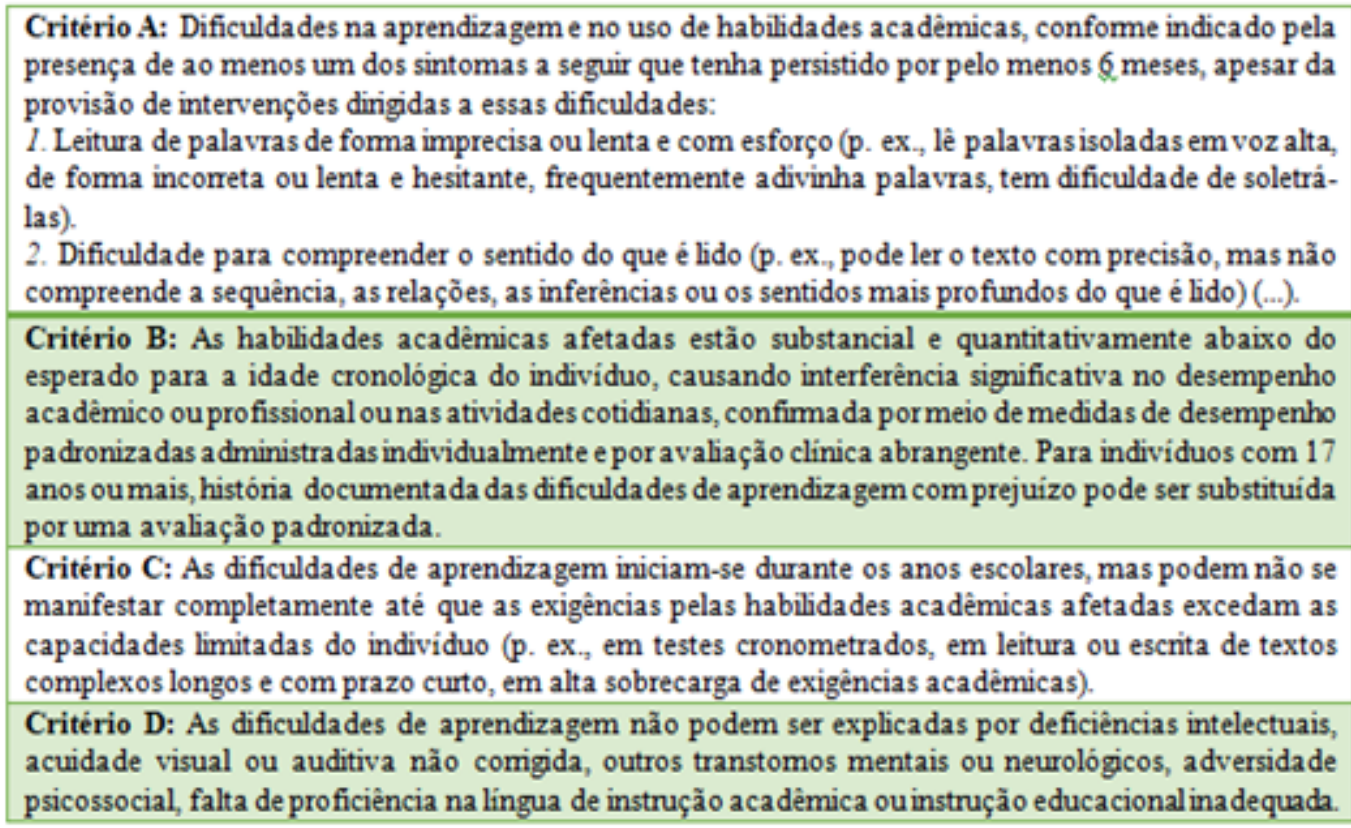

Fonte: APA (2013, p. 67) - Adaptado

O critério A apresenta como ponto principal o enunciado "ocorrência de sintomas persistentes", o que nos parece uma tentativa de facilitar a complicada discriminação entre o que se entende por transtorno e dificuldade de aprendizagem, corroborando com já-ditos sobre a Dislexia, de que se trataria de um quadro não transitório, que persiste. O que o DSM-5 reacentua em relação ao que estava posto, diz respeito a uma definição mais objetiva do que seria essa persistência e como medi-la. Nesse caso, persistente passa a ser o que persiste, por um período superior a seis meses, mesmo com algum tipo de suporte. A intenção discursiva empregada no rótulo persistente pretende naturalizar o transtorno, a partir de um parâmetro bem objetivo e aparentemente fácil de mensurar (contar os meses decorridos), para sustentar que sua caracterização é de ordem biológica e intrínseca ao sujeito. Sabe-se que, até então, o modelo tradicional de diagnóstico era baseado na observação da discrepância QI-rendimento, no qual os valores de QI (quociente intelectual) eram comparados ao desempenho na leitura.

Deste modo, a determinação do diagnóstico da Dislexia se transforma radicalmente. Passa-se de um diagnóstico dado à priori, no qual se observa a criança fracassando ano após

${ }^{3} \mathrm{O}$ critério (A) inclui a descrição de dificuldades nos domínios da escrita e da aritmética, além da leitura, sendo as primeiras excluídas do quadro e da análise por não fazerem parte do escopo dessa pesquisa, que se foca especificamente na dislexia. 
ano, sem nenhum tipo de apoio, e que após submetê-la a uma avaliação transversal, a lauda como disléxica, para um diagnóstico construído longitudinalmente, onde, ao sinal de qualquer dificuldade, se intervém com a criança por um período determinado e caso ela não supere as dificuldades anteriormente apresentadas, a Dislexia é confirmada, o que à primeira vista parece ser um avanço.

Analisando mais atentamente o discurso posto no manual, vê-se que essa estratégia, na verdade, revela-se potencialmente mais medicalizadora do que a proposta anterior, por pelo menos duas razões. Primeiramente pela vagueza a respeito da intervenção dirigida a ser oferecida à criança, já que há um silenciamento sobre quem faria a intervenção, a partir de que metodologia, frequência ou concepção de leitura, dando margem para que estas sejam ineficazes ou insuficientes e nesse caso não servindo como parâmetro para diferenciação entre quadros extrínsecos e intrínsecos, como pretendido por tal critério. Esse silenciamento e $o$ "vácuo" de discussões sobre o tipo de atendimento desvela a compreensão do que seja leitura, linguagem e sujeito. Dado os dissonantes efeitos de sentido desses conceitos para os interlocutores envolvidos nesse campo, esses espaços vazios são preenchidos pelo discurso dominante que, por sua posição assimétrica de poder, tira proveito desses não-ditos (BAKHTIN, 2014).

Ao descrever os sintomas da Dislexia, o manual revela, ainda, partir de uma concepção de língua(gem) enquanto código e de leitura enquanto decodificação (interlocutor passivo). Alerta-se aqui para o reducionismo quando se parte dessa concepção. Afinal, tanto o texto oral quanto o texto escrito (leitura) são dirigidos a um interlocutor específico e os sentidos do enunciado são construídos na prática dialógica, portanto, não fixos, nem predeterminados. Nesse sentido, ler e compreender estão diretamente relacionados à significação da enunciação que, por sua vez, é inseparável da situação concreta em que se realiza, ou seja, a leitura envolve diferentes sentidos, a partir da interação dialógica entre o leitor e o texto (interlocutor) e dos usos com/sobre/da língua(gem).

Outro ponto que merece destaque é a rigidez no estabelecimento de um tempo para intervenção sem, no entanto, esclarecer com base em que esse período foi estabelecido; em que contexto e por quem seria realizada; com qual frequência e duração a intervenção deveria ocorrer; ou ainda se em modalidade individual ou coletiva. Mais uma vez esses não-ditos têm algo a dizer, têm um sentido implícito, expõem a ideia de sujeitos homogêneos, assim como seus sintomas e suas patologias. Essa cristalização revela a intenção do discurso materializado e oficializado pelo manual, de servir como um mecanismo do controle da classe médica sobre os sujeitos. Assim, aos capturados pelo diagnóstico, resta resignarem-se a serem controlados, 
submeterem-se à administração de uma ação e responder a ela conforme o esperado (estímulo-resposta-reforço), como se práticas leitoras e relação do sujeito com a língua(gem)/leitura, não fossem construídas sócio-historicamente, como se fossem controláveis e pudessem ser pré-determinadas. Se assim fosse, as professoras na escola alfabetizariam todos os alunos da sala em um mesmo tempo previamente estabelecido e todos os estudantes teriam o mesmo percurso.

O outro ponto obscurecido por detrás do critério A está relacionado à instituição da noção de risco que, por sua vez, conduz cada vez mais prematuramente à identificação precoce. Novamente, parece vantajosa a possibilidade de identificar o quanto antes a ocorrência de problemas relacionados à aprendizagem. Todavia, há de se considerar que essa ideia despretensiosa reverbera ideologias que entendem o "fracasso escolar" e analfabetismo como uma "praga" que deve ser eliminada e controlada, a partir de campanhas de leitura e alfabetismo desvinculadas de qualquer reflexão sobre as desigualdades sociais, as práticas de letramento, diferentes valores atribuídos à escola e os diferentes modos de transmissão do capital cultural.

Preocupa, ainda, o estado de vigilância em que a criança é posta, o fato de cada passo ter que ser dado no "tempo certo", mais uma vez a partir de uma padronização. Preocupa não se considerar, sem relativização obviamente, que cada sujeito tenha respeitado o seu tempo e nem mesmo aguardar o tempo biológico de maturação, critério antes essencial e agora totalmente abandonado.

É assim que o discurso aparentemente ingênuo do conceito de risco e do diagnóstico precoce, conjuntamente com a classificação do DSM, configuram-se estratégias de biopoder e materializam a medicalização da infância (MARTINHAGO, 2018; ELIASSEN, 2018). Dessa forma, nota-se nesse documento a atuação das forças centrípetas ${ }^{4}$, forças de homogeneização, ideologicamente marcadas (BAKHTIN, 2014).

O critério $\mathrm{B}$ indica que a investigação da Dislexia deverá ser pautada em medidas quantitativas e padronizadas, a fim de mensurar o desempenho do sujeito em relação a sua faixa etária. A preocupação que este critério gera diz respeito à desconsideração de fatores sociais, ao mesmo tempo em que hipervaloriza o biológico, uma vez que a idade se sobrepõe à trajetória escolar do sujeito. Além disso, é sabido que medidas padronizadas muito pouco

\footnotetext{
${ }^{4} \mathrm{Na}$ perspectiva bakhtiniana, concepção assumida aqui neste artigo, se assume que há duas forças antagônicas que atuam sobre a língua. Forças centrífugas que atuam a favor da unificação, homogeneização e da normatização, e forças centrípetas, as quais promovem de desunificação, dinamização e heterogeneidade (BAKHTIN, 2014).
} 
contribuem para a compreensão de como o sujeito opera com/na/sobre a linguagem, que é um fenômeno vivo e inerente à interação social (BAKHTIN, 2014).

Sabe-se que a ênfase dada ao uso de estratégias de avaliação quantitativas e padronizadas orienta-se a partir de discursos fundamentados em explicações neurobiológicas, as quais reduzem a processamentos cerebrais fenômenos constitutivamente complexos, como a língua(gem)/leitura. Tal conduta revela-se um tanto quanto perversa, uma vez que impõe aos sujeitos um único modo de análise sobre seus sintomas, lhes nega o direito a optar por outros modos de interpretação sobre o processo de apropriação da leitura, visto que práticas naturalísticas e qualitativas são desprestigiadas. Ressalte-se aqui que os sujeitos se constituem no social, a partir da interação verbal e também pela relação que é estabelecida com seus sintomas. Dessa maneira, como a criança é vista e significada pelo outro produz efeito sobre sua subjetividade.

Vê-se que os rótulos elegidos para esse critério, “[...] medidas quantitativas e padronizados", buscam validar apenas os ditos discursos baseados em evidências. Mas vale lembrar que "[...] a noção de eficácia na Medicina Baseada em Evidências (MBE) está associada ao tratamento em condições de mundo ideal, ou seja, a supressão dos sintomas" (DUNKER; NETO, 2011, p. 622).

O critério B menciona, ainda, uma avaliação clínica abrangente. Contudo não aponta o que se entende por essa avaliação. Seria uma investigação conduzida por um único profissional, que se aprofunde nos diversos aspectos relacionados à aprendizagem, ou uma ampla equipe de profissionais, na qual cada um em sua especificidade analise os diferentes fatores que se relacionam à Dislexia? E é desse modo, com toda a vagueza e imprecisão, que o DSM-5, considerado a "bíblia da psiquiatria", portanto enunciadora de verdades inquestionáveis, conduz a diagnósticos equivocados, sendo subserviente à medicalização. Diagnósticos esses que, na maioria das vezes, silenciam a voz da escola (a voz do professor), a voz de outros profissionais, vozes que atuariam a favor de forças centrífugas e que ressoariam de encontro ao discurso hegemônico de viés clínico/biológico (BAKHTIN, 2014).

O critério C diz respeito ao período de aparecimento dos sintomas da Dislexia, sendo manifestado, mais frequentemente, quando a criança entra na escola, embora possa ser diagnosticado também na idade adulta, na medida em que os conhecimentos e as exigências se ampliem. A APA, ao assinalar a Dislexia dessa forma, sugere, por exemplo, que estudantes, mesmo sem queixas anteriores, ao ingressarem na universidade e diante de dificuldades com gêneros discursivos típicos do contexto acadêmico, possam ser classificados disléxicos. Ou ainda, que adultos em situações de stress, como por exemplo em avaliações ou 
provas aplicadas num tempo limitado, em casos de resultados insatisfatórios, possuiriam o Transtorno de Leitura. Assim, a Dislexia poderia manifestar-se em todos os ciclos da vida: antes (por meio dos sinais de risco); durante (com sintomas típicos); e depois de concluída a escolarização (em situações específicas), ou seja, os sujeitos estão sempre na mira do DSM-5, em via de serem medicalizados.

Caponi (2014) refere que o fato de as fronteiras entre o que é normal e patológico serem tão instáveis, ambíguas e difusas, acaba por facilitar a medicalização de comportamentos tidos como indesejáveis, e o DSM, consciente dessa fragilidade e da força do seu discurso, parece tirar proveito desse fato, expandindo, para além do período de alfabetização e do contexto escolar, o aparecimento da Dislexia.

O último critério diagnóstico, o critério D, elenca os fatores de exclusão, configurando um modelo de diagnóstico diferencial, na medida em que se prescreve que sejam excluídos comprometimentos outros. Vê-se aqui uma preocupação coerente: descartar fatores que possam ocasionar ou interferir no processo de apropriação de leitura para garantir que se trata da Dislexia. No entanto, essa tarefa parece-nos um tanto quanto ambiciosa, considerando a natureza da leitura e ainda mais pela dificuldade de avaliar e excluir aspectos subjetivos.

Agora, nem mesmo questões tidas como mais objetivas são tão fáceis de observar, ainda mais se considerarmos o contexto do Brasil, onde o acesso às políticas de saúde nem sempre é assegurado. Para excluir um déficit auditivo, faz-se necessário ao menos um otorrinolaringologista e um fonoaudiólogo. Para descartar dificuldade visual, há a necessidade de um oftalmologista. Eliminar deficiências intelectuais e transtornos mentais ou neurológicos demanda profissionais da psicologia, psiquiatria e neurologia. Sem falar nos demais aspectos. A propósito, como seria avaliada, considerando a exigência do DSM-5 quanto ao uso de testes padronizados, a ocorrência de adversidades psicossociais, falta de proficiência na língua materna, instrução educacional inadequada?

Vale ressaltar que a realidade da educação brasileira diverge muito do contexto de produção em que o manual foi discutido, os Estados Unidos da América. Diante esse cenário, pode-se falar em instrução acadêmica adequada? Nesse sentido, parece que o diagnóstico da Dislexia é direcionado para as classes mais vulneráveis economicamente. Ao pobre, que já não tem acesso a exames e profissionais especializados, e que muitas vezes não tem acesso a uma formação educacional de qualidade, é negado também o direito à normalidade. Mesmo que o contexto no qual ele está inserido não favoreça a aprendizagem. Do outro lado, a burguesia, provida naturalmente de todos os recursos que o capital pode oferecer, livra os seus filhos da etiqueta da burrice, como muitos sujeitos diagnosticados com Dislexia se 
reconhecem ou são denominados, garantindo assim a manutenção do seu status quo. Dessa maneira, a medicalização da educação, materializada, nesse caso, pelo discurso do DSM-5, é mais uma ferramenta que promove a desigualdade e exclusão social.

Além dos critérios diagnósticos, o DSM-5 inclui especificadores de gravidade da Dislexia (Figura 2). Esse parâmetro refere-se ao momento da avaliação, podendo se diferenciar ao longo da vida do indivíduo.

Figura 2 - Quadro de especificadores de gravidade da Dislexia propostos pelo DSM-5

\begin{tabular}{|c|l|}
\hline GRAVIDADE & \multicolumn{1}{c|}{ DIFICULDADES APRESENTADAS } \\
\hline Leve & $\begin{array}{l}\text { Alguma dificuldade em aprender habilidades em um ou dois dominios acadêmicos, } \\
\text { mas com gravidade suficientemente leve que permita ao individuo ser capaz de } \\
\text { compensar ou funcionar bem quando lhe são propiciados adaptações ou serviços de } \\
\text { apoio adequados, especialmente durante os anos escolares. }\end{array}$ \\
\hline Moderada & $\begin{array}{l}\text { Dificuldades acentuadas em aprender habilidades em um ou mais dominios } \\
\text { acadêmicos, de modo que é improvável que o individuo se tome proficiente sem } \\
\text { alguns intervalos de ensino intensivo e especializado durante os anos escolares. } \\
\text { Algumas adaptaços ou serviços de apoio por pelo menos parte do dia na escola, no } \\
\text { trabalho ou em casa podem ser necessános para completar as atividades de forma } \\
\text { precisa e eficiente. }\end{array}$ \\
\hline Drave \\
$\begin{array}{l}\text { Dificuldades graves em aprender habilidades afetando vánios dominios acadêmicos, } \\
\text { de modo que é improvável que o individuo aprenda essas habilidades sem um ensino } \\
\text { individualizado e especializado continuo durante a maior parte dos anos escolares. } \\
\text { Mesmo comum conjunto de adaptações ou serviços de apoio adequados em casa, na } \\
\text { escola ou no trabalho* o individuo pode não ser capaz de completar todas as } \\
\text { atividades de forma eficiente. }\end{array}$ \\
\hline
\end{tabular}

Fonte: APA (2013, 67-68) - Adaptado

Desse modo, a determinação da gravidade é mensurada por meio do impacto funcional presumidamente decorrente das dificuldades e pela necessidade de adaptações ou intervenções. Assim, uma Dislexia leve permitiria que o sujeito superasse suas dificuldades, desde que com algum tipo de suporte. Os casos moderados exigiriam necessariamente adaptações e intervenções mais intensivas. E a Dislexia grave imputaria um acompanhamento sistemático e rigoroso, sem assegurar como resultado uma leitura funcional e independente. Neste último caso, o sujeito com Dislexia grave é aprisionado numa posição cristalizada, em que há pouco ou nenhum espaço para melhora e movimentação em direção a um leitor ideal e efetivo.

E esse discurso, por tratar-se de um discurso oficial, logo, superestimado, acaba servindo de punição para o "portador", que deverá adaptar-se e submeter-se a intervenções prolongadas, mesmo sem uma garantia de melhora e desresponsabilizando o sistema de ensino e o professor, que terá uma justificativa simplificada do porquê seu aluno não lê: a Dislexia (ELIASSEN, 2018). E dizer que um sujeito não aprende por uma incapacidade própria é criar processos que irão estigmatizar o indivíduo, que será condicionado a 
intervenções médico-políticas de sujeição, de tutela e de controle construídas pelos discursos psiquiátricos (MOYSÉS; COLLARES, 2013). Além disso, medicalizar nesse cenário significa ignorar o que o sintoma quer revelar, é suprimir seu significado e desconsiderar o contexto em que ele ocorre (MARTINHAGO, 2018).

E ainda na tentativa de esgotar todo o conhecimento sobre a Dislexia, o DSM-5 apresenta o que chama de consequências funcionais do transtorno específico de aprendizagem, dentre as quais ele cita: baixo desempenho acadêmico; maiores taxas de evasão; menores taxas de educação superior; níveis altos de sofrimento psicológico; pior saúde mental geral; desemprego; subemprego; baixa renda e suicidalidade. Colocar o suicídio dentre as consequências da Dislexia, tão somente por ela ser considerada um problema "neurobiológico", exibe claramente a intencionalidade da APA em alardear toda a sociedade quanto aos perigos da Dislexia, corroborando ainda mais com a estigmatização dos sujeitos que fracassam na escola e a proliferação de discursos que legitimam a exclusão social e educacional.

Pensar que dificuldades escolares, sejam elas de origem orgânica ou social, possam ser determinantes para o fracasso escolar e social, para o desemprego, para a depressão, demonstra certa leviandade e imprudência, visto que a única perspectiva vislumbrada seria a morte, o suicídio. Assim, diante de uma doença tão condenatória parece não restar nada além de extirpá-la (ELIASSEN, 2018).

Essa visão, no entanto, revela o propósito de excluir para depois incluir, sendo que essa "falsa inclusão" seguirá a lógica de explorar para manter a desigualdade social que alimenta o sistema capitalista. Diante disso, a comunidade escolar deve rever seu modus operandi e ser cautelosa com os encaminhamentos que faz dos alunos para fora da escola, levando sempre em questão a partir de que concepção trabalham os profissionais que realizam diagnóstico, bem como de que modo esses leem o DSM-5. Para que assim evite-se submeter os estudantes a diagnósticos equivocados e dispositivos de medicalização, os quais podem repercutir de modo substancial na trajetória escolar e de vida desses sujeitos.

Desse modo, vê-se que os critérios sugeridos pelo DSM-5 para o diagnóstico da Dislexia, apesar de mascararem-se por trás de um discurso científico, neutro e cauteloso, apresentam lacunas, contradições e representam uma ideologia medicalizadora. Nesse sentido, o Cronotopo da Dislexia no DSM-5 desenrola-se num cenário complexo que se alterna entre a clínica e a escola. Esses espaços, engendrados, influenciam-se mutuamente, cabendo à clínica o papel de determinar os parâmetros de normalidade, para depois a escola identificar os "sinais do problema", que devolve à clínica para que avalie, ateste e por fim a escola que 
valida o discurso médico. Esse jogo ocorre na "era dos transtornos", num tempo em que "uma escola excludente", incapaz de lidar com as diferenças em sala de aula, vale-se do argumento da MBE, legitimando o déficit neurobiológico. No momento de precarização da educação, de polarização de ideologias, de escassez de políticas públicas e de perda de direitos constitucionais.

\section{Considerações finais}

Este estudo objetivou analisar o modo como a Dislexia é apresentada no DSM-5 e os efeitos produzidos sobre a medicalização do processo de apropriação da leitura. Para tanto, focou-se no Transtorno Específico da Aprendizagem com prejuízo na leitura, o qual trata da Dislexia. Pesquisas nessa área mostram-se cada vez mais fundamentais, dada a reverberação do discurso médico, materializado no texto do DSM, na comunidade científica e entre os profissionais de saúde e educação, implicando diretamente na medicalização da educação. Um dos pontos que não se pode perder de vista é que a leitura do DSM-5, o que ele representa e como seu discurso prolifera "extramuros", não é sequer conhecido pela grande maioria dos profissionais da educação.

Nesse sentido é que a dúvida do professor se o aluno é "disléxico", que parte inicialmente da escola para a clínica, a ela retorna, com a confirmação de um transtorno neurobiológico laudado e baseado no DSM-5. Contudo, o professor desconhece que o DSM-5 apresenta uma versão da Dislexia que desconsidera a história e o contexto sociocultural no qual os estudantes ou adultos em circunstâncias não escolares manifestam ou têm produzido sintomas na leitura. A ideologia em que o documento se baseia se insere numa perspectiva biologizante, na qual os problemas específicos à aprendizagem do ler decorrem unicamente de desordens neurobiológicas e, portanto, podem ser aferidos facilmente, por meio de medidas padronizadas. O documento considera, ainda, uma visão homogeneizante de sujeitos e de língua(gem)/leitura, bem como menospreza a existência das desigualdades sociais e oportunidades educacionais.

As consequências desse modo de olhar têm desdobramentos significantes, que não apenas marcam a trajetória escolar, mas também contribuem com a configuração de uma história que passa a ser marcada pela incapacidade (Dislexia) e não pela possibilidade (sujeito em processo de aprendizagem).

Desvela-se, dessa maneira, a urgência pela mobilização da sociedade acerca dos perigos e prejuízos das classificações diagnósticas que acarretam, consequentemente, na 
medicalização da educação, dada a necessidade da luta por uma sociedade que reconheça a diversidade e singularidade, também em relação ao modo de aprender. Mais do que estratégias de embate, faz-se necessária a promoção de um espaço reflexivo que permita, especialmente aos educadores, um olhar verdadeiramente ampliado sobre os escolares, acolhendo o sujeito e as dificuldades que ele apresenta, mas, sobretudo, o considere um leitor (ainda em construção) com potencial para apropriar-se da linguagem escrita.

\section{REFERÊNCIAS}

\section{AMERICAN PSYCHIATRIC ASSOCIATION. Diagnostic and statistical manual of} mental disorders. 5. ed. Arlington, VA: American Psychiatric Association, 2013. (DSM-5)

ARAÚJO, A. C; NETO, F. N. A nova classificação americana para os transtornos mentais - o DSM-5. Revista Brasileira de Terapia Comportamental e Cognitiva, São Paulo, v. 16, n. 1, p. 67-82, 2014. Disponível em:

http://pepsic.bvsalud.org/scielo.php?script=sci_arttext\&pid=S1517-55452014000100007. Acesso em: 29 fev. 2020.

AZEVEDO, L. J. C. Medicalização das infâncias: entre os cuidados e os medicamentos. Psicologia USP, São Paulo, v. 29, n. 3, p. 451-458, 2018. Disponível em: http://www.scielo.br/scielo.php?script=sci abstract\&pid=S010365642018000300015\&lng=en\&nrm=iso\&tlng=pt. Acesso em: 29 fev. 2020.

BAKHTIN, M. M. Questões de literatura e estética: a teoria do romance. 7. ed. São Paulo: Hucitec, 2014.

CAPONI, S. A propósito das classificações psiquiátricas: o DSM e suas classificações. Grandes temas do conhecimento - Psicologia, n. 23, p. 44-50, 2015. Disponível em: https://www.researchgate.net/publication/283120272_O_DSM_e_suas_dificuldades. Acesso em: 29 fev. 2020.

CAPONI, S. O DSM-V como dispositivo de segurança. Physis: Revista de Saúde Coletiva, v. 24, p. 741-763, 2014. Disponível em: http://www.scielo.br/scielo.php?pid=S010373312014000300741\&script=sci_abstract\&tlng=pt. Acesso em: 29 fev. 2020.

CHRISTOFARI, A. C; FREITAS, C. R; BAPTISTA, C. Medicalização dos modos de ser e de aprender. Educação \& Realidade, Porto Alegre, v. 40, n. 4, p. 1079-1102, 2015. DOI: https://doi.org/10.1590/2175-623642057

DUNKER, C. Subjetivações e gestão dos riscos na atualidade: reflexões a partir do DSM-5. Revista Epos, v. 5, n. 1, p. 181-190, 2014. Disponível em: http://pepsic.bvsalud.org/scielo.php?script=sci_arttext\&pid=S2178-700X2014000100010 Acesso em: 29 fev. 2020; 
DUNKER, C.; NETO, F. A crítica psicanalítica do DSM-IV - breve história do casamento psicopatológico entre psicanálise e psiquiatria. Rev. Latinoam. Psicopat. Fund., São Paulo, v. 14, n. 4, p. 611-626, 2011. DOI: https://doi.org/10.1590/S1415-47142011000400003

ELIASSEN, E. S. A discursivização do diagnóstico da Dislexia: da teoria à prática. Dissertação (Mestrado em Linguística). Florianópolis: Centro de comunicação e Expressão, Universidade Federal de Santa Catarina, 2018;

FOUCAULT, M. História da sexualidade I: A vontade de saber. Rio de Janeiro, RJ: Graal, 1977.

GIROTO, C. R. M.; ARAUJO, L. A; VITTA, F. C. F. Discursivização sobre "doenças do não aprender" no contexto educacional inclusivo: o que dizem os professores de Educação

Infantil? Revista IberoAmericana de Estudos em Educação, Araraquara, v. 14, n. esp. 1, p. 807-825, abr., 2019. Disponível em:

https://periodicos.fclar.unesp.br/iberoamericana/article/view/12208. Acesso em: 29 fev.2020.

MARTINHAGO, F. TDAH nas redes sociais: caminhos para a medicalização da infância.

Psicología, Conocimiento y Sociedad, v. 8, n. 2, p. 95-117, 2018. DOI:

http://dx.doi.org/10.26864/pcs.v8.n2.6

MARTINHAGO, F; CAPONI, S. Controvérsias sobre o uso do DSM para diagnósticos de transtornos mentais. Physis, v. 29, n. 2, p. 1-19, 2019. Disponível em:

http://www.scielo.br/pdf/physis/v29n2/0103-7331-physis-29-02-e290213.pdf. Acesso em: 29 fev. 2020.

MOUSINHO, R; NAVAS, A. L. Mudanças apontadas no DSM-5 em relação aos transtornos específicos de aprendizagem em leitura e escrita. Rev Deb Psiq, v. 6, n. 3, p. 38-45, 2016.

MOYSÉS, M. A. A; Collares, C. A. L. Controle e medicalização da infância. Revista Desidades, n.1, ano 1. NIPIAC. UFRJ. p. 11-21, 2013. Disponível em:

https://revistas.ufrj.br/index.php/desidades/article/viewFile/2456/2090. Acesso em: 29 fev. 2020.

\section{Como referenciar este artigo}

ELIASSEN, E. S.; SANTANA, A. P. O. O discurso sobre a Dislexia no DSM-5 e suas implicações no processo de medicalização da educação. Revista Ibero-Americana de Estudos em Educação, Araraquara, v. 15, n. esp. 5, p. 2883-2898, dez. 2020. e-ISSN: 19825587. DOI: https://doi.org/10.21723/riaee.v15iesp5.14564

Submetido em: 10/01/2020

Revisões requeridas em: $25 / 05 / 2020$

Aprovado em: 30/10/2020

Publicado em: 01/12/2020 